\title{
Ergogenic effects of quercetin supplementation in trained rats
}

\author{
Rafael A Casuso ${ }^{1}$, Antonio Martínez-Amat ${ }^{1 *}$, Emilio J Martínez-López ${ }^{3}$, Daniel Camiletti-Moirón², \\ Jesus M Porres ${ }^{2}$ and Pilar Aranda ${ }^{2}$
}

\begin{abstract}
Background: Quercetin is a natural polyphenolic compound currently under study for its ergogenic capacity to improve mitochondrial biogenesis. Sedentary mice have exhibited increased endurance performance, but results are contradictory in human models.
\end{abstract}

Methods: We examined the effects of six weeks of endurance training and quercetin supplementation on markers of endurance performance and training in a rodent model. Rats were randomly assigned to one of the following groups: placebo+sedentary (PS), quercetin+sedentary (QS), placebo+endurance training (PT) and quercetin +endurance training (QT). Quercetin was administered at a dose of $25 \mathrm{mg} / \mathrm{kg}$ on alternate days. During six weeks of treatment volume parameters of training were recorded, and after six weeks all groups performed a maximal graded $\mathrm{VO}_{2}$ max test and a low-intensity endurance run-to-fatigue test.

Results: No effects were found in $\mathrm{VO}_{2}$ peak ( $\left.p>0.999\right)$, nor in distance run during low-intensity test, although it was $14 \%$ greater in QT when compared with PT $(P=0.097)$. Post-exercise blood lactate was increased in QT when compared with PT ( $p=0.023)$ and also in QS compared with PS ( $p=0.024)$.

Conclusions: This study showed no effects in $\mathrm{VO}_{2}$ peak, speed at $\mathrm{VO}_{2}$ peak or endurance time to exhaustion after six weeks of quercetin supplementation compared with placebo in trained rats. Quercetin was show to increase blood lactate production after high-intensity exercise.

\section{Background}

Flavonoids are a large family of phenolic compounds or polyphenols with wide therapeutic applications [1]. Quercetin is one of the most widely spread naturally occurring flavonoids, found in onions, garlic, cabbage, leek, broccoli, apples, blueberries, tea and red wine [2]. It is known that quercetin may exhibit anti-oxidant properties due to its chemical structure, particularly the presence and location of the hydroxyl $(-\mathrm{OH})$ substitutions [3]. Despite the fact that after long-term intake there is a wide distribution of quercetin (including its metabolites) in all tissues [4], toxic effects have not been reported until the dose reached $157 \mathrm{mg}$ per $\mathrm{kg} / \mathrm{d}$ [5].

Quercetin might improve endurance performance since it is known that some polyphenols like quercetin [6] and resveratrol [7] improve aerobic capacity of skeletal muscle by promoting mitochondrial biogenesis in

\footnotetext{
*Correspondence: amamat@ujaen.es

'Department of Health Sciences, University of Jaén, Jaén E-23071, Spain

Full list of author information is available at the end of the article
}

mice. A psychostimulant effect of quercetin has also been reported in vitro [8] in a manner similar to that of caffeine [9], but this effect was not found in human subjects [10]. Quercetin has also been shown to reduce illness after strenuous exercise [11], as corroborated by Davis et al. [12] in a mice model. However, these antiinflamatory effects seen in vivo are not as powerful as those previously described in vitro [13]. The differences are even greater when the in vivo data is obtained from athletes [14-16].

Quercetin supplementation improves running time to fatigue by stimulating mitochondrial biogenesis in mice [6]. However, this effect has not been observed in humans [16-18]. Research has shown improvements of $3.9 \%$ in $\mathrm{VO}_{2}$ peak and $13.2 \%$ in time to fatigue [19], as well as $2.9 \%$ in a maximal 12 -minute test after an hour of preload [18] in untrained subjects. These findings are in contrast to those of previous studies $[11,17,20]$. When athletes are studied, most research has failed to find an ergogenic effect $[15,16]$, in contrast to that of a study of

\section{() Biomed Central}


elite cyclists, who exhibited an improvement of their aerobic performance [21]. Finally, effects of quercetin on pre-exercise and post-exercise blood lactate have not been reported [22].

Based on the data provided, the question arises: could quercetin be an ergogenic supplement for athletes or untrained subjects? Our primary goal is to study, for the first time and using a rat model, the effects of both endurance training and chronic quercetin supplementation on 1) endurance capacity, $\mathrm{VO}_{2}$ peak, and lactate production, 2) endurance training progress, and 3) distance covered in a low-intensity treadmill test and in a highintensity treadmill test.

\section{Methods}

\section{Animals and experimental design}

Thirty-three young (three week old) male Wistar rats were randomly allocated into four groups: quercetin and endurance training $(\mathrm{QT}, \mathrm{n}=9)$, placebo and endurance training (PT, $\mathrm{n}=8)$, quercetin and sedentary $(\mathrm{QS}, \mathrm{n}=8)$, and placebo and sedentary (PS, $\mathrm{n}=8$ ). Animals, with an initial body weight of $150(\mathrm{SD}=10) \mathrm{g}$, were housed in individual stainless steel metabolism cages. The cages were located in a well-ventilated thermostatically controlled room $\left(21 \pm 2^{\circ} \mathrm{C}\right)$, with relative humidity ranging from 40 to $60 \%$. A reverse $12 \mathrm{~h}$ light- $12 \mathrm{~h}$ dark cycle (08.00-20.00 hours) was implemented to allow exercise training during the day. Throughout the experimental period, all rats consumed water and food ad libitum. Two weeks before the experimental period, rats were allowed to adapt to the diet and experimental conditions, and a week before the experimental period, rats had three days of acclimation to the treadmill. Body weight was measured twice per week during this time. After six weeks of treatment we performed two different exercise tests. Tests were carried out after the treatment so that we could compare four different conditions without assessing the effect of training. The reason for choosing a rat model is that a previous study showed that sedentary mice exhibited higher endurance performance with quercetin intake than with placebo [6]. All experiments were undertaken according to the Directional Guides Related to Animal Housing and Care (European Community Council, 1986), and all procedures were approved by the Animal Experimentation Ethics Committee of the University of Jaén.

\section{Quercetin treatment}

Rats were supplemented, during the training period, with quercetin (QU995; Quercegen Pharma, Newton, MA, USA) on alternate days at a dose of $25 \mathrm{mg} / \mathrm{kg}$. This dose has been reported to improve mitochondrial biogenesis and endurance capacity in sedentary mice [6]. Quercetin was diluted in a $1 \%$ solution of methilcellulose, and was administered using a metal gavage. Oral gavage was performed to ensure that $25 \mathrm{mg} / \mathrm{kg}$ of quercetin was introduced into the stomach. Quercetin also contained vitamins $B 3$ and $C$, which have been shown to increase the bioavailability of quercetin (personal communication, Quercegen Pharma). The PT and PS groups were also supplemented with methilcellulose and vitamin B3 and C with the same concentration as in QT and QS.

\section{Training protocol}

Trained animals were exercised five days per week during six weeks on a motorized treadmill (Panlab TREADMILLS for five rats LE 8710R). We followed a modification of the protocol of Davies et al [23]. Animals ran at a constant speed of $44 \mathrm{~cm} / \mathrm{s}$ and at $10 \%$ grade. The first day's training session was 20-minutes long, and every two days the work period was increased by five minutes. On the last day of the fifth week they were required to run for a full 80 minutes. This work duration was maintained during the sixth week. The untrained group was exercised at the same speed and grade for only 10 minutes twice per week, in order to ensure that they were able to perform the tests performed at the end of the treatment.

Twenty-four hours after the last training session, all animals performed a graded high-intensity treadmill test to determine $\mathrm{VO}_{2}$ peak using a treadmill gas analyzer (Model LE405, Panlab/Harvard Apparatus) previously calibrated with mixtures of $\mathrm{O} 2$ and $\mathrm{CO} 2$ at different concentrations. After an initial two minutes with no grade at $22 \mathrm{~cm} / \mathrm{s}$, treadmill speed was increased by $11 \mathrm{~cm} / \mathrm{s}$ every two minutes. The test was finished when the rat was exhausted and located at the end of the treadmill, on the shock bar, for 5 seconds, when rats were quickly removed [24]. $\mathrm{VO}_{2}$ peak was defined as the highest 20" interval recorded during the test. Blood lactate was measured before and immediately after the test using a Lactate-Pro analyzer, blood was taken from a small cut in the rat's tail.

After twenty-four hours of recovery a low-intensity endurance test was performed. Each rat was required to run to exhaustion at $44 \mathrm{~cm} / \mathrm{s}$ at a $10 \%$ grade. The test finished when the animal was visibly exhausted, not able to maintain the appropriate pace, and this resulted in a rising frequency of landings on the electrical shock grid [24]. The endpoint was marked by the rat's inability to return to the treadmill belt, and to stand on a flat surface.

\section{Statistical methods}

Treatment effect between trained (QT vs PT) and sedentary (QS vs PS) groups was analyzed with a t test for independent samples, using study groups as independent variables and each of the performance parameters 
measured as dependent variables (Weight, $\mathrm{VO}_{2}$ peak, $\mathrm{vVO}_{2}$ peak, maximum speed achieved, time of endurance test, distance run and distance run until $\mathrm{RQ}=1$, and $\mathrm{VO}_{2}$ at exhaustion). Lactate production measured before and after the maximal incremental treadmill test was analyzed using a two-way repeated measures ANOVA, with groups as between-subject variable and exercise time as within-subject variable. When the effect was significant, post hoc analysis was performed and adjustment done through the Bonferroni confidence interval. The level of significance was $\mathrm{P} \leq 0.05$ for the t-test and $\mathrm{P} \leq 0.008$ in post hoc Bonferroni's comparisons $(\mathrm{P}=0.008$ needed for significance with an experimentwise alpha of 0.05 using Bonferroni adjustment in alpha for six comparisons). All analyses were performed using the Statistical Package for Social Sciences (SPSS, version 19.0 for Windows; SPSS, Inc., Chicago, IL, USA).

\section{Results}

\section{Training progress}

The training protocol and the effect of time on the meters run is presented in Figure 1. The QT and PT groups were subjected to a six-week duration training with an increase of five minutes every two days up to a maximum of 80 minutes, which represented an average increase of the load between intervals of 11.9 and $10.6 \%$ in QT and PT respectively. The final training volume increased by $399 \%$ to 349\% in QT and PT compared with baseline. There were no differences in the distance run by the two groups at any time of training $(\mathrm{P}>0.05)$. The average/day of meters walked were 986 and 1002 in the QT and PT groups respectively. Although the relationship between training time and distance covered showed an almost linear fit in both groups ( $\mathrm{R} 2=0.992$ and 0.986 ) for QT and PT respectively, there was a sligh improvement in the performance of the QT group.

\section{Endurance capacity}

There were no significant difference in exercise performance between the quercetin and placebo trials. Although the QT group ran for 5.91\% longer (Figure 2) and 14\% further (Figure 3B) than the PT group, there were no significant differences in either time $[\mathrm{P}=0.351$, Power $=0.147]$ or distance $[\mathrm{P}=0.051$, Power $=0.512)]$.

\section{Maximal incremental test}

During the incremental test $\mathrm{VO}_{2}$ peak, speed at $\mathrm{VO}_{2}$ peak and maximum speed achieved did not differ between quercetin and placebo conditions (Table 1). There were no differences between the final weight after treatment, as shown in Table 1. Although the distance achieved by QT was $18.6 \%$ greater than PT this result was not significant $[\mathrm{P}=0.102$, Power $=0.380]$ (Figure $3 \mathrm{~A}$ ).

Figure $4 \mathrm{~B}$ shows that the QT group ran for $56.1 \%$ longer before reaching $\mathrm{RQ}=1$ compared with the $\mathrm{PT}$ group, but this effect was not significant $[\mathrm{P}=0.222$, Power $=0.213]$. Similar results are illustrated by Figure $4 \mathrm{~A}$, in which $\mathrm{VO}_{2}$ at exhaustion does not differ after the high-intensity test for the quercetin and placebo exercise groups $(P=0.069$, Power $=0.448)$. Lactate production was analyzed (pre- and post-high-intensity test) using repeated measures ANOVA, where we observed a group effect $\mathrm{P}=0.001$, Power $=0.967$ and a group interaction per time unit $\mathrm{P}=0.001$, Power $=0.977$. Specifically, lactate production

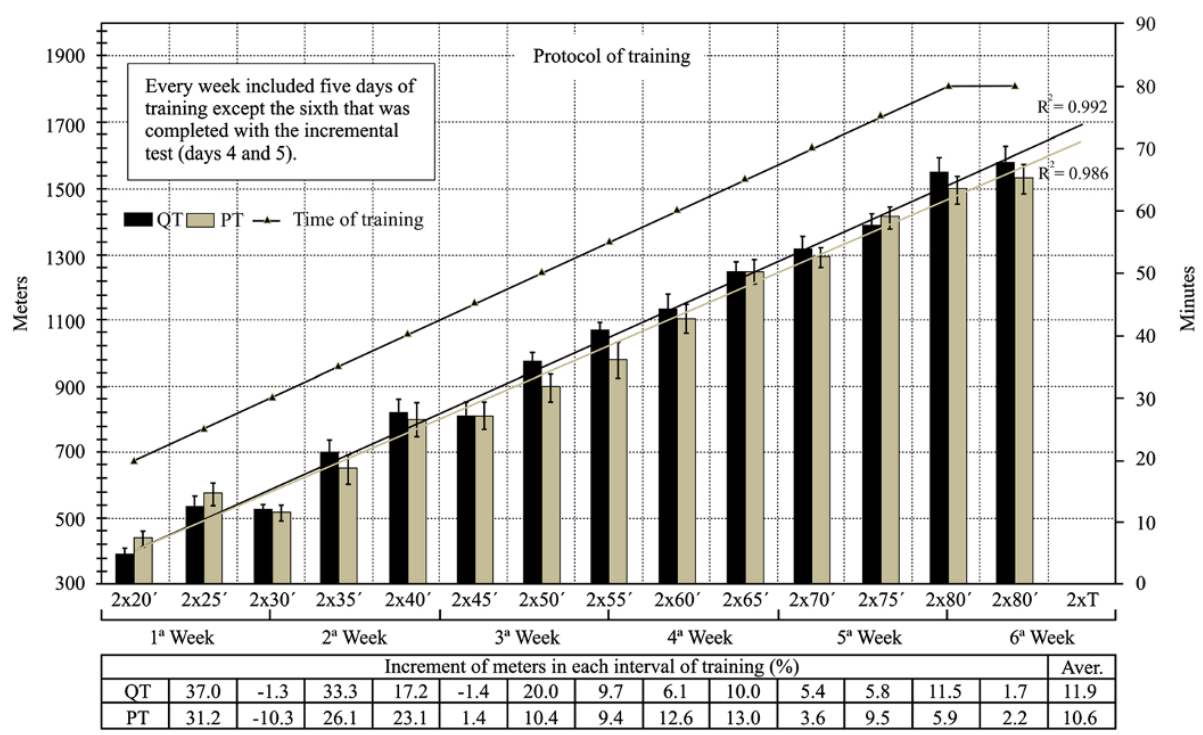

Figure 1 Training protocol of six weeks for rats. No significant difference $(P>0.05)$ in distance run between QT and PT at any stage of training ' $=$ Minutes, Aver = Average, $\mathrm{T}=$ Application of tests. The percentage of increase in distance run was computed as ((interval - previous interval) / previous interval) $\times 100$. 


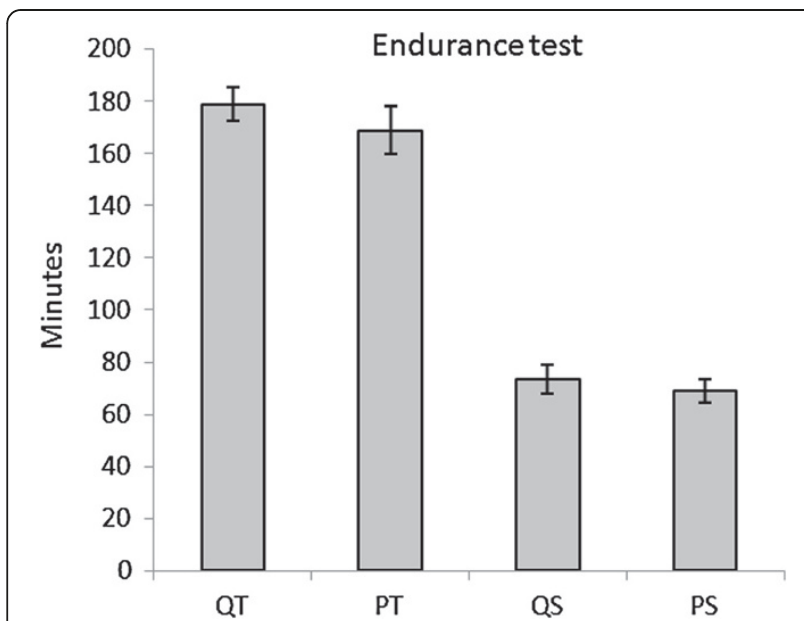

Figure 2 Time run until exhaustion in the low-intensity endurance regime. $T$ - test for independent samples reported no significant differences between QT and PT or QS and PS ( $P>0.05)$.

immediately after the high-intensity test was increased in the QT and QS groups compared with the PT and PS groups $(\mathrm{P}=0.004)$ [Figure 5]. No differences were found in lactate production between groups prior to the highintensity test $(\mathrm{P}>0.05)$. Lactate production was significantly increased in each group $(\mathrm{P}<0.001$ in $\mathrm{QT}, \mathrm{QS}$ y PS) and $(\mathrm{P}=0.004$ in either $\mathrm{PT})$ at the end of the high-intensity test (data not shown).

\section{Discussion}

A recent study evaluated the effects of short-term quercetin supplementation on exercise performance in mice [6] and demonstrated a significant increase in endurance capacity and mitochondrial biogenesis in comparison with placebo groups. Using a rat model, no significant performance effect (VO2 peak, endurance capacity and training parameters) was measured in trained rats with a quercetin dose of $25 \mathrm{mg} / \mathrm{kg}$ on alternative days compared with placebo.
The endurance training protocol used in this study was a modification of a widely used protocol in the literature $[23,25,26]$. As shown in Figure 1, distance run increased with time. These data suggest that the training workload was well adjusted, since a plateau in the training volume is a sign of overtraining [27]. No difference was found in the average daily distance run between the QT and PT groups. $\mathrm{VO}_{2}$ peak values in rats vary depending on the methodological test used or on their weight [28]. Our results show that six weeks of quercetin supplementation did not increase $\mathrm{VO}_{2}$ peak or $\mathrm{VO}_{2}$ at exhaustion in sedentary or trained rats. It must be noted that our protocol did no alter inclination in order to examine the maximum speed achieved. Protocols that do not use an incline are known to induce a lower $\mathrm{VO}_{2}$ peak than others with $15^{\circ}-20^{\circ}$ inclination $[28,29]$. However, our results were similar to those recently reported [17], but were in contrast with the ones that reported an increase of $\mathrm{VO}_{2}$ peak by quercetin in sedentary humans [19]. Speed at $\mathrm{VO}_{2}$ peak was also analyzed in this experiment, with no change reported in the quercetin groups. We hypothesized that quercetin would increase $\mathrm{VO}_{2}$ peak due to its ability to increase mitochondrial biogenesis in mice (6). However, as described above, no differences were observed in any groups on measures related to oxygen uptake by quercetin supplementation. These results are similar to those obtained by Bigelman et al [30]. There are several potential reasons for these results: firstly, $\mathrm{VO}_{2}$ peak is influenced by muscle mitochondrial oxidative capacity, but relative to endurance capacity, it is limited to a greater extent by oxygen delivery via the cardiovascular system [31]. Secondly, larger doses over extended periods using added flavonoids such as eppigallocatechin gallate (EGCG) may augment quercetin's effects on mitochondrial biogenesis. This could be a more appropriate supplement to increase oxygen consumption [16]. However, previous work did not find any ergogenic effect of quercetin and EGCG supplementation in a moderately trained sample [30].
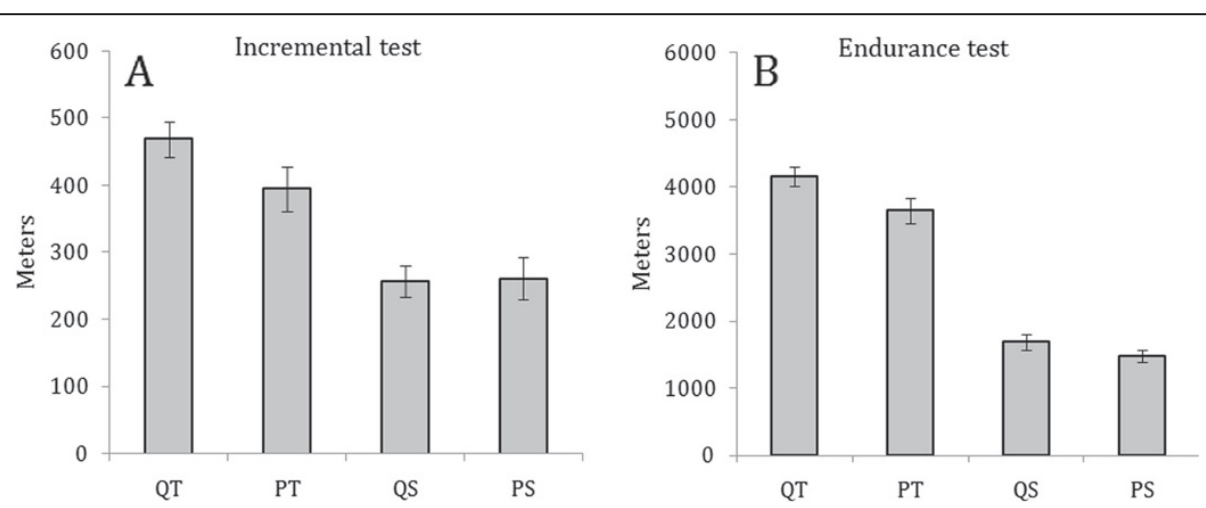

Figure 3 Distance run until exhaustion in A) high-intensity incremental test and B) low-intensity endurance test. T-test for independent samples reported no significant differences between $Q T$ and PT or QS and PS (P>0.05). 
Table 1 Mean value (standard deviation) after incremental maximal test

\begin{tabular}{|c|c|c|c|c|c|c|c|c|c|c|c|c|}
\hline & \multicolumn{6}{|c|}{ Trained } & \multicolumn{6}{|c|}{ Sedentary } \\
\hline & QT & PT & $t$ & df & $\mathbf{P}$ & Power & QS & PS & $t$ & df & $\mathbf{P}$ & Power \\
\hline WEIGHT (g) & $352.89 \pm 31.25$ & $367.25 \pm 24.41$ & 1.045 & 15 & 0.312 & 0.161 & $379.25 \pm 52.91$ & $366.63 \pm 8.97$ & 0.595 & 7.298 & 0.570 & 0.086 \\
\hline $\begin{array}{l}\mathrm{VO}_{2} \mathrm{MAX} \\
(\mathrm{ml} / \mathrm{kg} / \mathrm{min})\end{array}$ & $63.55 \pm 8.58$ & $58.62 \pm 7.38$ & 1.272 & 14.990 & 0.223 & 0.219 & $65.12 \pm 8.21$ & $61.87 \pm 5.51$ & 0.929 & 14 & 0.369 & 0.139 \\
\hline $\begin{array}{l}/ \mathrm{vVO}_{2} \mathrm{MAX} \\
(\mathrm{cm} / \mathrm{s})\end{array}$ & $47.89 \pm 8.17$ & $48.50 \pm 16.18$ & 0.100 & 15 & 0.922 & 0.051 & $46.88 \pm 13.21$ & $46.63 \pm 10.98$ & 0.041 & 14 & 0.968 & 0.052 \\
\hline $\begin{array}{l}\text { MAX. VEL } \\
(\mathrm{cm} / \mathrm{s})\end{array}$ & $95.11 \pm 7.40$ & $87.50 \pm 9.65$ & 0.837 & 15 & 0.086 & 0.405 & $71.63 \pm 8.68$ & $71.63 \pm 11.01$ & 0.002 & 14 & 0.998 & 0.050 \\
\hline
\end{tabular}

Compared values for trained (QT vs PT) and sedentary groups (QS vs PS). T-test for independent samples reported no significant differences between QT and PT or QS and PS. $\mathrm{VO}_{2} \mathrm{MAX}$ : Maximum oxygen uptake; $\mathrm{VVO}_{2} \mathrm{MAX}$ : Velocity at $\mathrm{VO}_{2}$ max; MAX.VEL: Maximal velocity achieved. df: degrees of freedom. Power: statistical power.

To examine additional ergogenic effects of quercetin in rats, oxygen consumption and carbon dioxide production were measured during the incremental exercise test. This enabled the calculation of RQ. In all groups of rats, the average RQ remained fairly constant and did not differ between groups (data not shown). When $\mathrm{VCO}_{2}$ is greater than $\mathrm{VO}_{2}(\mathrm{RQ}>1.0)$, this point of inflection is correlated with blood lactate accumulation [32]. QT group showed a trend to run longer before reaching an RQ of 1.0 (Figure 4B) indicating that these rats were able to use oxidative metabolism for a longer period.

Fatigue in the endurance test is thought to arise primarily from limitations in the periphery, like the cardiovascular system and muscles [6]. Although it has been reported that antioxidant supplementation may decrease endurance performance [25], the trained groups showed an increase in time to fatigue of $244.96 \%$ and $244.93 \%$ for QT and PT respectively when compared to PS. However, in contrast with others [6], we did not observe an improvement in QS. When compared to trained groups, there was a non-significant increase of $5.91 \%$ in the QT group in time to fatigue. Despite being non-significant, this result was related to recently published results by Kesser et al. [33].
We employed two different types of exercise (a low intensity endurance capacity test and a maximal graded intensity test). Although both are commonly used exercise models, the stimuli are totally different. During the treadmill running endurance test mice run at a given intensity until they can no longer maintain the pace and end up on the electrical shock grid $[24,25]$. The performance in this type of exercise is known to be related to the oxidative capacity of muscles. However, during the maximal progressive intensity test, rats achieved higher velocities, a performance reflecting their capacity to use glycogen as a source of fuel. Distance run to exhaustion was recorded during these two different regimes (Figure 3). Under the high-intensity regime (test used to analyze oxygen consumption) the QT group ran $(18,6 \%)$ longer than PT. Under the low-intensity regime (endurance test) QT ran $14 \%(\mathrm{p}=0.097)$ further than PT. These results were not significant, however they demonstrated a trend that may become significant after a longer treatment.

Although no effects have been previously reported [22], the present study demonstrated that quercetin had an effect on blood lactate immediately after exhaustion. When the QT and QS groups reached exhaustion, their blood lactate levels were elevated when compared with
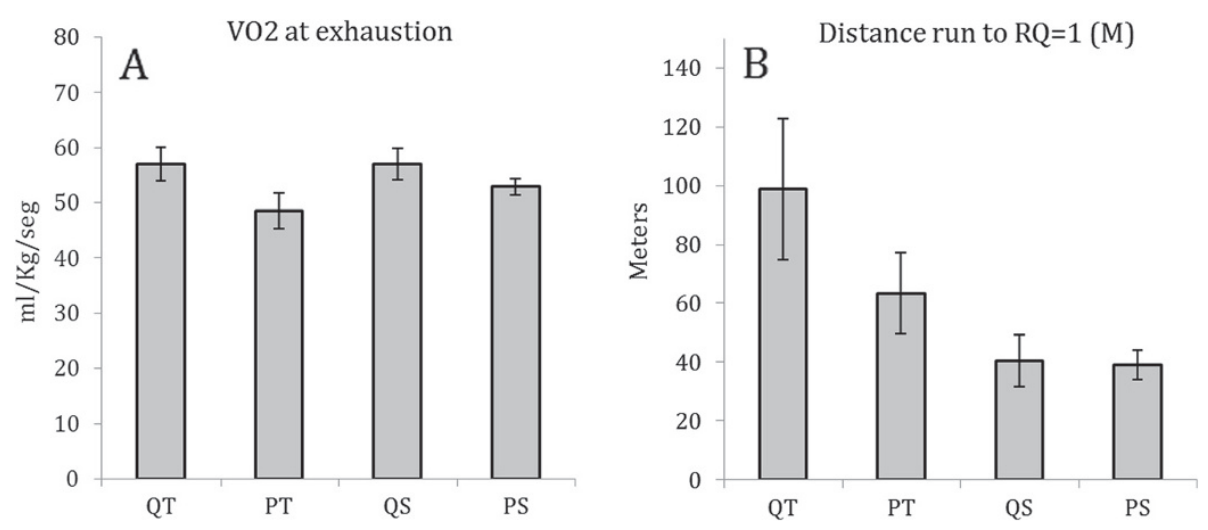

Figure $4 \mathrm{~A}) \mathrm{VO}_{2}$ at the end of the high-intensity incremental test B) Distance run until $\mathrm{RQ}=1$. T-test for independent samples reported no significant differences between QT and PT or QS and PS $(P>0.05)$. 


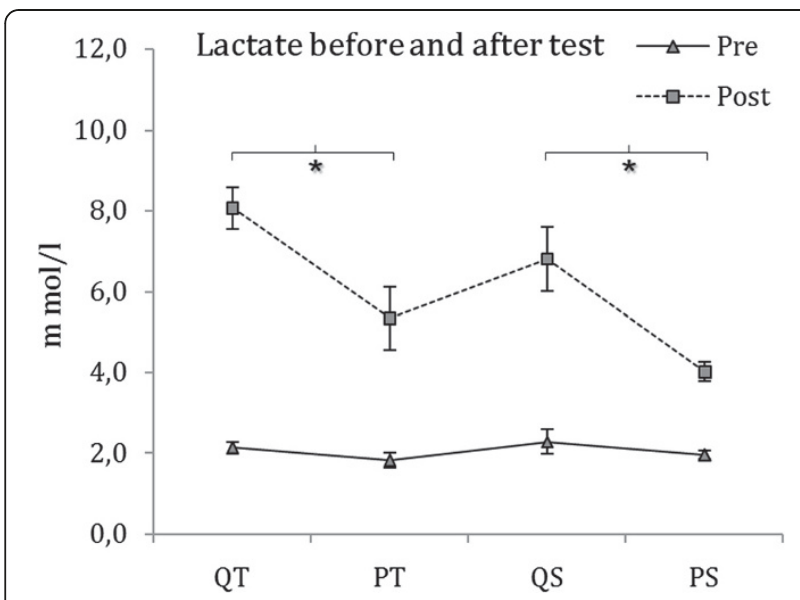

Figure 5 Blood lactate pre- and post-exercise using a two-way repeated measures ANOVA. ( $P=0.008$ needed for significance with an experiment-wise alpha of 0.05 using Bonferroni adjustment in alpha for six comparisons) * Post lactate differences $(P=0.004)$ in $\mathrm{QT}$ vs PT and QS vs PS.

PT and with PS respectively (Figure 5). These elevated blood lactate levels were an indication of enhanced glycolysis and lactate production in the skeletal muscle [30] in the quercetin supplemented groups that had run to exhaustion. However, there are other possible reasons that may explain the quercetin effects in addition to improvements in glycolytic flux. The psychostimulant effects of quercetin [8] could increase effort at high intensities and this could result in an increased lactate production. However, further experiments may corroborate this quercetin effect by measuring glycogen depletion in muscle and liver during high-intensity exercise.

In summary, no effects were measured in $\mathrm{VO}_{2}$ peak, speed at $\mathrm{VO}_{2}$ peak or endurance time to exhaustion after six weeks of quercetin supplementation compared with placebo in trained rats. No effects were found either in sedentary rats supplemented with quercetin compared with placebo. However, a trend was visible regarding increased performance by quercetin supplementation in some parameters like distance run until exhaustion or distance run until $R Q=1$. Perhaps after longer treatment, like eight or ten weeks, this effect could be significant. For the first time we have detected an increase in blood lactate production by quercetin, although more research is needed on this topic. No effects on exercise performance were found but this will need to be verified by further studies examining muscle physiology.

\section{Limitations and strengths}

The present study has several limitations that must be mentioned. First, the present physiological results obtained in rats must be confirmed in human subjects after longterm quercetin ingestion, since our results cannot be extrapolated to the potential effects over months in trained human subjects. Also, there is a lack of evidence regarding how much quercetin must be supplemented for it to exert its ergogenic effects, although $25 \mathrm{mg} / \mathrm{kg}$ is thought to be a good start. In addition, the six-week protocol applied may be insufficient to observe any ergogenic effect, and in fact there are some parameters that started exhibiting a trend and might be significant after 8-13 weeks of treatment. Finally, the lower statistical power observed in most of our results suggests to be cautious in interpreting them, future research with larger samples are needed to draw definitive conclusions. On the other hand, this is the first research that has analyzed the effect of quercetin on both sedentary and trained rats, hopefully paving the road for studies intended to find out if quercetin supplementation can enhance performance in trained athletes.

\section{Competing interests}

The authors declare no competing interest.

\section{Authors' contributions}

RAC was involved in the conception, design, acquisition and analysis of the data and drafting the manuscript, AM-A was involved in the conception, design, acquisition and analysis of the data and drafting the manuscript, EJM was involved in the conception, design, acquisition and analysis of the data and drafting the manuscript, DC-M was involved in the conception, design, acquisition and analysis of the data and drafting the manuscript, JMP was involved in the analysis of the data and drafting the manuscript and PA was involved in the conception, design, acquisition and analysis of the data and drafting the manuscript. All authors have given final approval of the version to be published.

\section{Acknowledgements}

We are grateful to all the members who has collaborated developing the present study, especially people helping in the field-work and all Department of Physiology. Also the authors gratefully acknowledge Milagros Galisteo for their advices.

\section{Author details}

'Department of Health Sciences, University of Jaén, Jaén E-23071, Spain. ${ }^{2}$ Department of Physiology, School of Pharmacy and Institute of Nutrition and Food Technology, University of Granada, Campus Universitario de Cartuja s/n, Granada 18071, Spain. ${ }^{3}$ Department of Music, Plastical Expression and Body Language, University of Jaén, Jaén E-23071, Spain.

Received: 4 June 2012 Accepted: 19 December 2012

Published: 14 January 2013

\section{References}

1. Middleton E, Kandaswami C, Theoharides TC: The effects of plant flavonoids on mammalian cells: implications for inflammation, heart disease, and cancer. Pharmacol Rev 2000, 52:673-751.

2. Manach C, Scalbert A, Morand C, Rémesy C, Jimenez L: Polyphenols: food sources and bioavailability. Am J Clin Nutr 2004, 79:727-747.

3. Hardwood M, Danielewska-Nikiel B, Borzelleca JF, Flamm GW, Lines TC: A critical review of the data related to the safety of quercetin and lack of evidence of in vivo toxicity, including lack of genotoxic/carcinogenic propierties. Food Chem Toxicol 2007, 45:2179-2205.

4. De Boer VC, Dihal AA, van der Woude H, Arts IC, Wolffram S, Alink GM, Rietjens IM, Keijer J, Hollman PC: Tissue distribution of quercetin in rats and pigs. J Nutr 2005, 135:1718-1725.

5. Azuma K, Ippoushi K, Terao J: Evaluation of tolerable levels of dietary quercetin for exerting its antioxidative effect in high cholesterol-fed rats. Food Chem Toxicol 2010, 48:1117-1122. 
6. Davis JM, Murphy EA, Carmichael MD, Davis B: Quercetin increases brain and muscle mitochondrial biogenesis and exercise tolerance. Am J Physiol Regul Integr Comp Physiol 2009, 296:R1071-R1077.

7. Lagouge M, Argmann C, Gerhart-Hines Z, Meziane H, lerin C, Daussin F, Mesadeq N, Milne J, Lambert P, Elliott P, Geny B, Laakso M, Puigserver P, Auwerx J: Resveratrol improves mitochondrial function and protects against metabolic disease by activating SIRT1 and PGC-1a. Cell 2006, 127:1109-1122.

8. Alexander SP: Flavonoids as antagonists at A1 adenosine receptors. Phytother Res 2006, 20:1009-1012.

9. Ferré $S$ : An update on the mechanisms of the psychostimulant effects of caffeine. J Neurochem 2008, 105:1067-1079.

10. Cheuvront SN, Ely BR, Kenefick RW, Michniak-Kohn BB, Rood JC, Sawka MN: No effect of nutritional adenosine receptor antagonists on exercise performance in the heat. Am J Physiol Regul Integr Comp Physiol 2009 296:R394-R401.

11. Nieman DC, Henson DA, Davis JM, Angela Murphy E, Jenkins DP, Gross SJ, Carmichael MD, Quindry JC, Dumke CL, Utter AC, MCAnulty SR, McAnulty LS, Tripplett NT, Mayer EP: Quercetin's influence on exercise-induced changes in plasma cytokines and muscle and leukocyte cytokine mRNA. J Appl Physiol 2007, 103:1728-1735.

12. Davis JM, Murphy EA, McClellan JL, Carmichael MD, Gangemi JD: Quercetin reduces susceptibility to influenza infection following stressful exercise. Am J Physiol Regul Integr Comp Physiol 2008, 295:R505-R509.

13. Vlachodimitropoulou E, Naftalin RJ, Sharp PA: Quercetin is a substrate for the transmembrane oxidoreductase Dcytb. Free Radic Biol Med 2010, 48:1366-1369.

14. McAnulty SR, MCAnulty LS, Nieman DC, Quindry JC, Hosick PA, Hudson MH, Still L, Henson DA, Milne GL, Morrow JD, Dumke CL, Utter AC, Triplett NT, Dibarnardi A: Chronic quercetin ingestion and exercise-induced oxidative damage and inflammation. Appl Physiol Nutr Metab 2008, 33:254-262.

15. Quindry JC, McAnulty SR, Hudson MB, Hosick P, Dumke C, McAnulty LS, Henson D, Morrow JD, Nieman D: Oral quercetin supplementation and blood oxidative capacity in response to ultramarathon competition. Int J Sport Nutr Exerc Metab 2008, 18:601-616.

16. Nieman DC, Henson DA, Maxwell KR, Williams AS, McAnulty SR, Jin F, Shanely RA, Lines TC: Effects of quercetin and EGCG on mitochondrial biogenesis and immunity. Med Sci Sports Exerc 2009, 41:1467-1475.

17. Cureton JK, Tomporowski PD, Sinhal A, Pasley JD, Bigelman KA, Lambourne K, Trilk JL, McCully KK, Arnaud MJ, Zhao Q: Dietary quercetin supplementation is not ergogenic in untrained men. J Appl Physio/ 2009, 107:1095-1104.

18. Nieman DC, Williams AS, Shanely RA, jin F, McAnuty SR, Triplett NT, Austin $M D$, Henson DA: Quercetin's influence on exercise performance and muscle mitochondrial biogenesis. Med Sci Sports Exerc 2010, 42:338-345.

19. Davis JM, Carlstedt CJ, Chen S, carmichael MD, Murphy EA: The dietary flavonoid quercetin increases $\mathrm{VO} 2 \mathrm{max}$ and endurance capacity. Int $J$ Sport Nutr Exerc Metab 2010, 20:56-62

20. Dumke CL, Nieman DC, Utter AC, Rigby MD, Quindry JC, Triplett NT, McAnulty SR, McAnulty LS: Quercetin's effect on cycling efficiency and substrate utilization. Appl Physiol Nutr Metab 2009, 34:993-1000.

21. MacRae HS, Mefferd KM: Dietary antioxidant supplementation combined with quercetin improves cycling time trial performance. Int J Sport Nutr Exerc Metab 2006, 16:405-419.

22. Ganio MS, Armstrong LE, Johnson EC, Klau JF, Ballard KD, Michniak-Kohn B, Kaushik D, Maresh CM: Effect of quercetin supplementation on maximal oxygen uptake in men and women. J Sports Sci 2010, 28:201-208.

23. Davies KJ, Packer L, Brooks GA: Biochemical adaptation of mitochondria, muscle, and whole-animal respiration to endurance training. Arch Biochem and Biophy 1981, 209:539-554.

24. Safdar A, Abadi A, Akhtar M, Hettinga BP, Tarnoplosky MA: miRNA in the regulation of skeletal muscle adaptation to acute endurance exercise in C57BI/6 J male mice. PLoS One 2009, 4(5):e5610. doi:10.1371/journal. pone.0005610.

25. Gómez-Cabrera MC, Domenech E, Romagnoli M, Romagnoli M, Arduini A, Borras C, Pallardo FV, Sastre J, Viña J: Oral administration of vitamin C decreases muscle mitochondrial biogenesis and hampers traininginduced adaptations in endurance performance. Am J Clin Nutr 2008, 87:142-149.
26. Georgieva K, Boyadjiev NP: Effects of nandrolone decanoate on VO2max, running economy, and endurance in rats. Med Sci Sports Exerc 2004, 36:1336-1341

27. Kadja L, Eimre M, Paju K, Roosimaa M, Podramägi T, Kaasik P, Pehme A Orlova E, Mudist M, peet N, Piirsoo A, Seene T, Gellerich FN, Seppet EK Impaired oxidative phosphorylation in overtrained rat myocardium. Exp Clin Cardiol 2010, 15:116-127.

28. Wisloff U, Helgerud J, Kemi OJ, Ellingsen O: Intensity-controlled treadmill running in rats: VO2 max and cardiac hypertrophy. Am J Physiol Heart Circ Physiol 2001, 280:H1301-H1310.

29. Kemi OJ, Loennechen JP, Wisloff U, Ellingsen O: Intensity-controlled treadmill running in mice: cardiac and skeletal muscle hypertrophy. J Appl Physiol 2002, 93:1301-1309.

30. Bigelman KA, Fan EH, Chapman DP, Freese EC, Trilk JL, Cureton KJ: Effects of six weeks of quercetin supplementation on physical performance in ROTC cadets. Mil Med 2010, 175:791-798.

31. Basset DR, Howley ET: Limiting factors for maximum oxygen uptake and determinants of endurance performance. Med Sci Sports Exerc 2000, 32:70-84.

32. Flynn JM, Meadows E, Fiorotto M, Klein WH: Myogenin regulates exercise capacity and skeletal muscle metabolism in the adult mouse. PLOS One 2010, 5(10):e13535. doi:10.1371/journal.pone.0013535.

33. Kressler J, Millard-Stafford M, Warren GL: Quercetin and endurance exercise capacity: a systematic review and Meta-analysis. Med Sci Sports Exerc 2011, 43:2396-2404.

\section{doi:10.1186/1550-2783-10-3}

Cite this article as: Casuso et al:: Ergogenic effects of quercetin supplementation in trained rats. Journal of the International Society of Sports Nutrition 2013 10:3.

\section{Submit your next manuscript to BioMed Central and take full advantage of:}

- Convenient online submission

- Thorough peer review

- No space constraints or color figure charges

- Immediate publication on acceptance

- Inclusion in PubMed, CAS, Scopus and Google Scholar

- Research which is freely available for redistribution 